\title{
Study on Dynamic Response of Straddle-Type Monorail Vehicle with Single-Axle Bogie Under Curve Condition
}

\author{
Liang XIN*, Zixue DU**, Junchao ZHOU***, Zhen YANG***, Zhouzhou XU*** \\ *Institute of Urban Rail, Chongqing Jiaotong University, Chongqing 400074, P. R. China, E-mail: xinlaero@163.com \\ **Institute of Urban Rail, Chongqing Jiaotong University, Chongqing 400074, P. R. China, \\ E-mail: aaadzx@163.com (Corresponding author) \\ ***Institute of Urban Rail, Chongqing Jiaotong University, Chongqing 400074, P. R. China \\ crossref http://dx.doi.org/10.5755/j02.mech.25319
}

\section{Introduction}

In recent years, with the development of economy and society, the urban traffic problems become more and more serious. Straddle-type monorail vehicles, as distinctive urban rail transit system, has the advantages of strong climbing ability, small turning radius, fast running speed, small floor area, safety and comfort, low noise and low cost, so that it has been applied in many cities [1-3].

Compared to subway vehicles of the traditional steel wheel-rail system, straddle-type monorail vehicles use rubber tire. The driving wheels contact the upper surface of the track beam, and the steering wheels and the stabilizing wheels distributed on both sides of the bogie contact the side surface of the track beam, as shown in Fig. 1[4]. Therefore, the dynamic response of straddle-type monorail also has unique characteristics. A lot of dynamic response of straddle-type monorails have been studied for by many researchers. Goda et al. [5] established the 9-DOF dynamic model of monorail vehicle considering the tire force of track irregularity, and carried out the spectrum analysis. Then, they [6] analyzed the influence of the longitudinal stiffness of the air spring, and the research shown that the force of the steering wheel and the slip rate of the driving wheel were smaller when the longitudinal stiffness of the air spring was low. Based on Lagrange's formulation for monorail trains, and a finite-element method for modal analysis of monorail bridges, Lee et al. [7] established a more detailed 15-DOF monorail bridge-train interaction system, and analyzed the effect of the train speed and the passenger loading on ride comfort. After that, Lee et al. [8] took the Osaka monorail steel structure bridge as the research object, derived a three-dimensional monorail bridge-train interaction system, and analytical results on dynamic response of the monorail train and bridge were compared with field-test data in order to verify the validity of the proposed analysis procedure. To assess the dynamic behavior of monorail-bridge system, Naeimi et al. [9] developed an innovative model of train-guide way interaction based on multibody dynamics and finite element simulation. At the same time, aiming at the curve condition of monorail vehicles, Goda et al. [10] developed a curving simulation. Based on the finite element method and energy method, Wang et al. [11] proposed an analytical procedure of dynamic interaction analysis of the straddle monorail bridge-vehicle coupling system, and analyzed the effects of speed, three kinds of loads and different radius of curvature on dynamic responses. In addition, the influence of wheel out of round on vehicles dynamic responses were studied in ref. [12-13].

All the above studies are based on the double-axle bogie model. At present, straddle type monorail vehicles mainly have two types, i.e., double-axle bogie model (Chongqing straddle monorail and Hitachi) and single-axle bogie model (Bombardier). Compared with the double-axle bogie model, the single-axle bogie model has a lot of advantages [4]. Firstly, due to the reduced number of tires and the use of hourglass springs, Bombardier Monorail300 has a significantly lower mass than Chongqing monorail and is easier to maintain. Secondly, Bombardier Monorail 300 has a vehicle height of $4.053 \mathrm{~m}$, about $1.1 \mathrm{~m}$ lower than Chongqing monorail vehicle. At last, the turning radius of Bombardier Monorail 300 can reach 46m, which has a huge advantage compared with the $100 \mathrm{~m}$ turning radius of Chongqing monorail.

Therefore, a 15-DOF dynamic model is established for straddle-type monorail vehicle with single-axle bogie, which consists driving wheels, steering wheels and stabilizing wheels. The motion equations of the straddletype monorail vehicle are derived using the Lagrange's equation, and the wheel-rail contact model and the curving track beam model are created. Compared with the test results, the accuracy of the method is verified. Finally, the dynamic response of straddle-type monorail vehicle under curve condition is analysed.

This paper is organized as follows: the 15-DOF dynamic model is established in Section 2, which consists driving wheels, steering wheels and stabilizing wheels. Section 3 does the track modelling and comparison between the calculation results and the test results is shown in Section 4. Section 5 describes the results and discussion and Section 6 concludes this paper.

\section{Dynamic model}

\subsection{Motion equations}

The dynamics model of straddle-type monorail vehicle includes three parts, one vehicle body and two bogies. Each bogie has 2 driving wheels, 4 steering wheels and 2 stabilizing wheels, as shown in Fig. 1. Fig. 2 shows the 15-DOF dynamic model of straddle-type monorail vehicle. The DOF variables of the vehicle body and bogies are presented in Table 1, and the notations of monorail vehicle dynamics model are stated in Table 2.

According to the Lagrange's equation, the motion equation of the vehicle can be described by Eq. (1). 
$\frac{d}{d t}\left(\frac{\partial T}{\partial \dot{q}_{j}}\right)-\frac{\partial T}{\partial q_{j}}+\frac{\partial U^{e}}{\partial q_{j}}+\frac{\partial U^{q}}{\partial \dot{q}_{j}}=Q_{j}$.

In Eq. (1) $T$ indicates kinetic energy; $U^{e}$ indicates elastic potential energy; $U^{q}$ indicates damping potential energy, $q_{j}$ is the generalized coordinate; $\left.\dot{(}\right)$ represents the derivation of time.
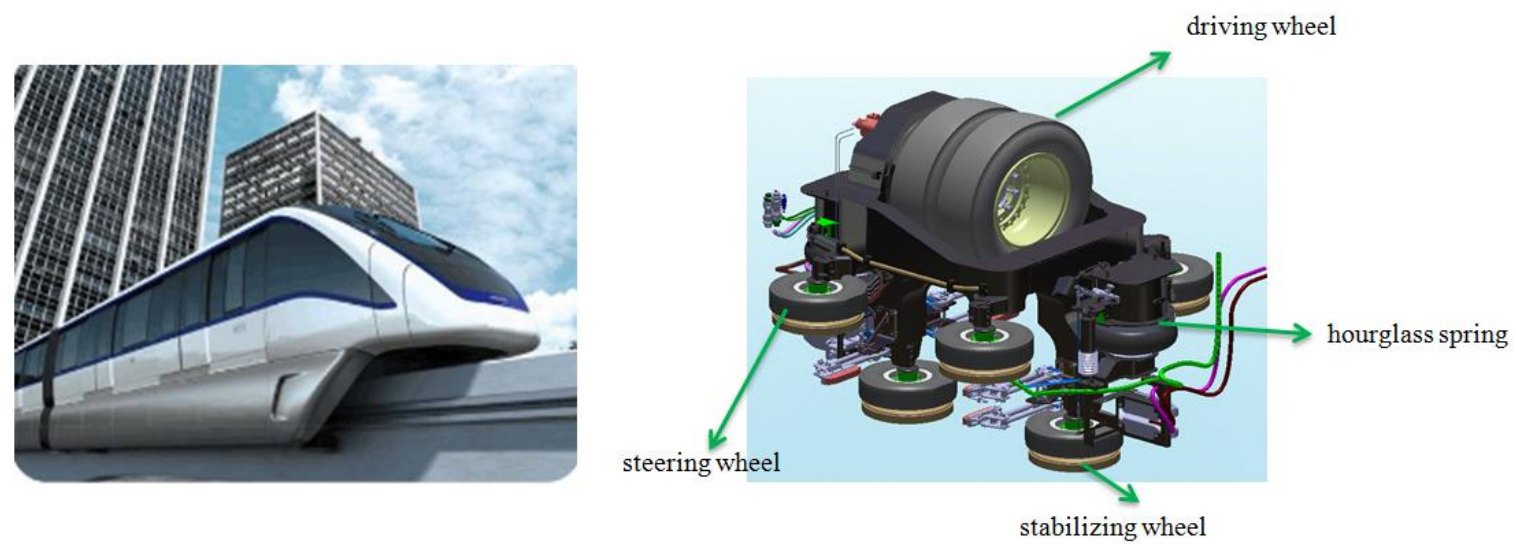

Fig. 1 Straddle-type monorail vehicle with single-axle bogie
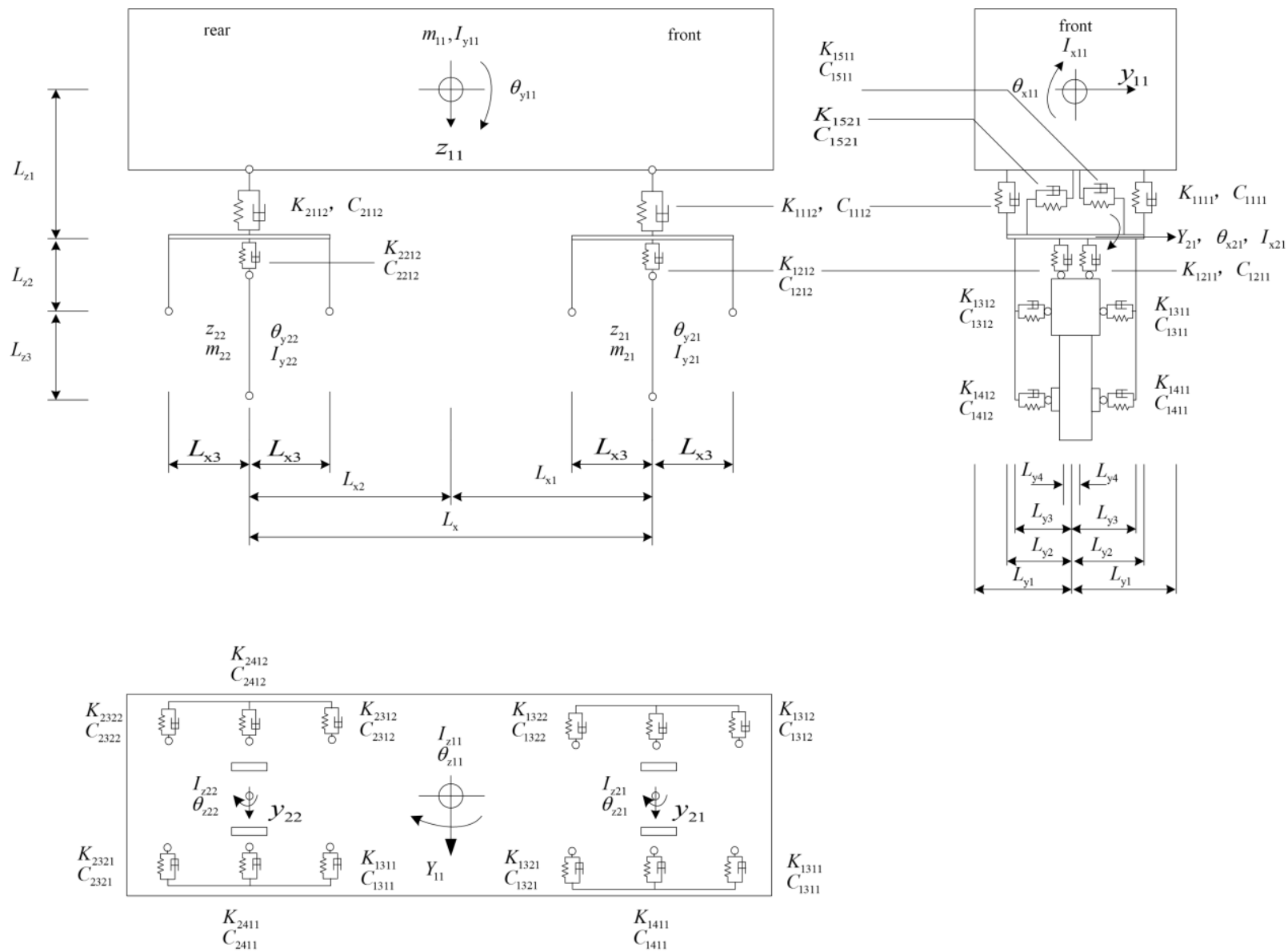

Fig. 2 15-DOF dynamics model of straddle-type monorail vehicle

Table 1

The DOF variables of the vehicle

\begin{tabular}{|c|c|c|c|c|c|}
\hline Vehicle parts & Lateral & Vertical & Rolling & Pitching & Yawing \\
\hline Vehicle body & $y_{11}$ & $z_{11}$ & $\theta_{x 11}$ & $\theta_{y 11}$ & $\theta_{z 11}$ \\
\hline Front bogie & $y_{21}$ & $z_{21}$ & $\theta_{x 21}$ & $\theta_{y 21}$ & $\theta_{z 21}$ \\
\hline Rear bogie & $y_{22}$ & $z_{22}$ & $\theta_{x 22}$ & $\theta_{y 22}$ & $\theta_{z 22}$ \\
\hline
\end{tabular}


Table 2

Notations of monorail vehicle dynamics model

\begin{tabular}{|c|c|}
\hline Descriptions & Notations \\
\hline Mass (vehicle and bogies) & $m_{11}, m_{21}, m_{22}$ \\
\hline $\begin{array}{c}\text { Stiffness of hourglass spring } \\
\text { (vertical) }\end{array}$ & $K_{1111}, K_{1112}, K_{2111}, K_{2112}$ \\
\hline Stiffness of driving wheel & $K_{1211}, K_{1212}, K_{2211}, K_{2212}$ \\
\hline Stiffness of steering wheel & $\begin{array}{l}K_{1311}, K_{1312}, K_{1321}, K_{1322}, \\
K_{2311}, K_{2312}, K_{2321}, K_{2322}\end{array}$ \\
\hline Stiffness of stabilizing wheel & $K_{1411}, K_{1412}, K_{2411}, K_{2412}$ \\
\hline $\begin{array}{c}\text { Stiffness of hourglass spring } \\
\text { (lateral) }\end{array}$ & $K_{1511}, K_{1512}, K_{2511}, K_{2512}$ \\
\hline $\begin{array}{c}\text { Damping of hourglass spring } \\
\text { (vertical) }\end{array}$ & $C_{1111}, C_{1112}, C_{2111}, C_{2112}$ \\
\hline Damping of driving wheel & $C_{1211}, C_{1212}, C_{2211}, C_{2212}$ \\
\hline Damping of steering wheel & $\begin{array}{l}C_{1311}, C_{1312}, C_{1321}, C_{1322}, \\
C_{2311}, C_{2312}, C_{2321}, C_{2322}\end{array}$ \\
\hline Damping of stabilizing wheel & $C_{1411}, C_{1412}, C_{2411}, C_{2412}$ \\
\hline $\begin{array}{l}\text { Damping of hourglass spring } \\
\text { (lateral) }\end{array}$ & $C_{1511}, C_{1512}, C_{2511}, C_{2512}$ \\
\hline
\end{tabular}

The equation of kinetic energy, elastic potential energy and damping potential energy are expressed by Eqs. (2) $-(4)$.

$$
\begin{gathered}
T=\frac{1}{2}\left\{m_{11}\left(\dot{y}_{11}^{2}+\dot{z}_{11}^{2}\right)+I_{x 11} \dot{\theta}_{x 11}^{2}+I_{y 11} \dot{\theta}_{y 11}^{2}+I_{z 11} \dot{\theta}_{z 11}^{2}+\right. \\
\left.+\sum_{i=1}^{2}\left(m_{2 i}\left(\dot{y}_{2 i}^{2}+\dot{z}_{2 i}^{2}\right)+\left(I_{x 2 i} \dot{\theta}_{x 2 i}^{2}+I_{y 2 i} \dot{\theta}_{y 2 i}^{2}+I_{z 2 i} \dot{\theta}_{z 2 i}^{2}\right)\right)\right\}, \\
U^{e}=\frac{1}{2} \sum_{i=1}^{2} \sum_{j=1}^{2} \sum_{n=1}^{2}\left(K_{i 1 j n} R_{i 1 j n}^{2} \delta_{1 j}+K_{i 2 j n} R_{i 2 j n}^{2} \delta_{1 j}+\right. \\
\left.+K_{i 3 j n} R_{i 3 j n}^{2}+K_{i 4 j n} R_{i 4 j n}^{2} \delta_{1 j}+K_{i 5 j n} R_{i 5 j n}^{2} \delta_{1 j}\right), \\
U^{q}=\frac{1}{2} \sum_{i=1}^{2} \sum_{j=1}^{2} \sum_{n=1}^{2}\left(C_{i 1 j n} \dot{R}_{i 1 j n}^{2} \delta_{1 j}+C_{i 2 j n} \dot{R}_{i 2 j n}^{2} \delta_{1 j}+\right. \\
\left.+C_{i 3 j n} \dot{R}_{i 3 j n}^{2}+C_{i 4 j n} \dot{R}_{i 1 j n}^{2} \delta_{1 j}+C_{i 5 j n} \dot{R}_{i j j n}^{2} \delta_{1 j}\right)_{j} .
\end{gathered}
$$

In Eqs. (2) - (4), the subscript $i$ is the vehicle bogie position ( $i=1,2$ are front and rear bogies); the subscript $j$ is the wheel position in the bogie ( $j=1,2$ are front and rear wheels); $n$ is the left and right sides of the vehicle ( $n=1,2$ are left and right sides); $R_{\text {imjn }}$ is the relative displacement; $\delta_{1 j}$ is Kronecker delta.

By substituting Eqs. (2) - (4) into Eq. (1), the motion equations of straddle-type monorail vehicle with single-axle bogie are obtained as shown in Eqs. (5) - (7).

The motion equations of vehicle body:

$$
\left\{\begin{array}{l}
m_{11}\left(\ddot{z}_{11}-V^{2} \varphi_{c q} / R_{c}\right)=\sum_{i=1}^{2} \sum_{j=1}^{2} \sum_{n=1}^{2}\left\{-K_{i 1 j n} R_{i 1 j n}-C_{i 1 j n} \dot{R}_{i 1 j n}\right\} \delta_{1 j} \\
m_{11}\left(\ddot{y}_{11}-g \varphi_{c q}\right)=\sum_{i=1}^{2} \sum_{j=1}^{2} \sum_{n=1}^{2}\left\{K_{i 5 j n} R_{i 5 j n}+C_{i 5 j n} \dot{R}_{i 5 j n}-K_{i 3 j n} R_{i 3 j n}-C_{i 3 j n} \dot{R}_{i 3 j n}-\left(K_{i 4 j n} R_{i 4 j n}-C_{i 4 j n} \dot{R}_{i 4 j n}\right) \delta_{1 j}\right\} \\
I_{x 11} \ddot{\theta}_{x 11}=\sum_{i=1}^{2} \sum_{j=1}^{2} \sum_{n=1}^{2}\left\{(-1)^{n} L_{y 2}\left(K_{i 1 j n} R_{i 1 j n}+C_{i 1 j n} \dot{R}_{i 1 j n}\right) \delta_{1 j}+L_{z 1}\left(K_{i 5 j n} R_{i 5 j n}+C_{i 5 j n} \dot{R}_{i 5 j n}\right) \delta_{1 j}+L_{z 1} g \varphi_{c q}\right\} \\
I_{y 11} \ddot{\theta}_{y 11}=\sum_{i=1}^{2} \sum_{j=1}^{1} \sum_{n=1}^{2}\left\{(-1)^{i} L_{x i}\left(K_{i 11 n} R_{i 11 n}+C_{i 11 n} \dot{R}_{i 11 n}\right)\right\} \\
I_{z 11} \ddot{\theta}_{z 11}=\sum_{i=1}^{2} \sum_{j=1}^{1} \sum_{n=1}^{2}\left\{-(-1)^{i} L_{x i}\left(K_{i 511} R_{i 511}+C_{i 511} \dot{R}_{i 511}\right)\right\}
\end{array}\right.
$$

The motion equations of front bogie:

$$
\left\{\begin{array}{l}
m_{21}\left(\ddot{z}_{21}-V^{2} \varphi_{c q f b} / R_{f b}\right)=\sum_{i=1}^{1} \sum_{j=1}^{1} \sum_{n=1}^{2}\left\{\left(K_{i j 1 n} R_{i j 1 n}+C_{i j 1 n} \dot{R}_{i j 1 n}\right)-\left(K_{i j 2 n} R_{i j 2 n}+C_{i j 2 n} \dot{R}_{i j 2 n}\right) \delta_{1 j}\right\} \\
m_{21}\left(\ddot{y}_{21}-g \varphi_{c q f b}\right)=\sum_{i=1}^{1} \sum_{j=1}^{2} \sum_{n=1}^{2}\left\{-K_{i 3 j n} R_{i 3 j n}-C_{i 3 j n} \dot{R}_{i 3 j n}-\left(K_{i 4 j n} R_{i 4 j n}+C_{i 4 j n} \dot{R}_{i 4 j n}\right) \delta_{1 j}+\left(K_{i 5 j n} R_{i 5 j n}+C_{i 5 j n} \dot{R}_{i 5 j n}\right) \delta_{1 j}\right\} \\
I_{x 21} \ddot{\theta}_{x 21}=\sum_{i=1}^{1} \sum_{j=1}^{2} \sum_{n=1}^{2}\left\{-(-1)^{n} L_{y 2}\left\{K_{i 1 j n} R_{i 1 j n}+C_{i 1 j n} \dot{R}_{i 1 j n}\right\} \delta_{1 j}+(-1)^{n} L_{y 4}\left\{K_{i 2 j n} R_{i 2 j n}+C_{i 2 j n} \dot{R}_{i 2 j n}\right\} \delta_{1 j}\right. \\
\left.\quad-L_{z 3}\left\{K_{i 4 j n} R_{i 4 j n}+C_{i 4 j n} \dot{R}_{i 4 j n}\right\} \delta_{1 j}\right\} \\
\ddot{I}_{y 21} \ddot{\theta}_{y 21}=0 \\
I_{z 21} \ddot{\theta}_{z 21}=\sum_{i=1}^{1} \sum_{j=1}^{2} \sum_{n=1}^{2}\left\{-(-1)^{i} L_{x 4}\left(K_{i 3 j n} R_{i 3 j n}+C_{i 3 j n} \dot{R}_{i 3 j n}\right)\right\}
\end{array}\right.
$$

The motion equations of rear bogie: 


$$
\left\{\begin{array}{l}
m_{22}\left(\ddot{z}_{22}-V^{2} \varphi_{c q f b} / R_{f b}\right)=\sum_{i=2}^{2} \sum_{j=1}^{1} \sum_{n=1}^{2}\left\{\left(K_{i j 1 n} R_{i j 1 n}+C_{i j 1 n} \dot{R}_{i j 1 n}\right)-\left(K_{i j 2 n} R_{i j 2 n}+C_{i j 2 n} \dot{R}_{i j 2 n}\right) \delta_{1 j}\right\} \\
m_{22}\left(\ddot{y}_{22}-g \varphi_{c q f b}\right)=\sum_{i=2}^{2} \sum_{j=1}^{2} \sum_{n=1}^{2}\left\{-K_{i 3 j n} R_{i 3 j n}-C_{i 3 j n} \dot{R}_{i 3 j n}-\left(K_{i 4 j n} R_{i 4 j n}+C_{i 4 j n} \dot{R}_{i 4 j n}\right)+\left(K_{i 5 j n} R_{i 5 j n}+C_{i 5 j n} \dot{R}_{i 5 j n}\right) \delta_{1 j}\right\} \\
I_{x 21} \ddot{\theta}_{x 21}=\sum_{i=2}^{2} \sum_{j=1}^{2} \sum_{n=1}^{2}\left\{-(-1)^{n} L_{y 2}\left\{K_{i 1 j n} R_{i 1 j n}+C_{i 1 j n} \dot{R}_{i 1 j n}\right\} \delta_{1 j}+(-1)^{n} L_{y 4}\left\{K_{i 2 j n} R_{i 2 j n}+C_{i 2 j n} \dot{R}_{i 2 j n}\right\} \delta_{1 j}\right. \\
\left.\quad-L_{z 3}\left\{K_{i 4 j n} R_{i 4 j n}+C_{i 4 j n} \dot{R}_{i 4 j n}\right\} \delta_{1 j}\right\} \\
I_{y 22} \ddot{\theta}_{y 22}=0 \\
I_{z 22} \ddot{\theta}_{z 22}=\sum_{i=2}^{2} \sum_{j=1}^{2} \sum_{n=1}^{2}\left\{-(-1)^{i} L_{x 4}\left(K_{i 3 j n} R_{i 3 j n}+C_{i 3 j n} \dot{R}_{i 3 j n}\right)\right\}
\end{array}\right.
$$

The relative displacements are described as follow:

$$
\begin{aligned}
& R_{i 1 j n}=z_{11}-z_{2 i}+(-1)^{n} \theta_{x 11} L_{y 2}- \\
& -(-1)^{n} \theta_{x 2 i} L_{y 2}-(-1)^{i} \theta_{y 11} L_{x i}, \\
& R_{i 2 j n}=z_{2 i}+(-1)^{n} \theta_{x 2 i} L_{v y 4}-W_{i 2 j n}, \\
& R_{i 3 j n}=y_{2 i}+(-1)^{j} \theta_{z 2 i} L_{x 3}-W_{i 3 j n}, \\
& R_{i 4 j n}=y_{2 i}+\theta_{x 2 i} L_{z 3}-W_{i 4 j n}, \\
& R_{i 5 j n}=y_{11}-y_{2 i}+(-1)^{n} \theta_{x 11} L_{z 1}+(-1)^{i} \theta_{z 11} L_{x i},
\end{aligned}
$$

where: $W_{\text {imjn }}(m=2,3,4)$ is displacement caused by uneven rail surface.

\subsection{Wheel-rail contact model}

The driving wheels, steering wheels and stabilizing wheels use rubber tire, which have obvious nonlinearity. Under curve condition, due to the guide function of the track beam, the driving wheel will be in the compound condition of longitudinal sliding, side sliding and roll. Driving wheel and rail contact model are expressed as follow:

$$
\begin{aligned}
& F_{i 2 j n}=\frac{1}{4}\left\{m_{11} g\left(1-\frac{L_{x i}}{L_{x}}\right)+m_{2 i} g\right\}+ \\
& +K_{i 2 j n} R_{i 2 j n}+C_{i 2 j n} \dot{R}_{i 2 j n} .
\end{aligned}
$$

Steering wheels and stabilizing wheels and rail contact model are expressed as follow:

$$
\begin{aligned}
& F_{i 3 j n}=K_{i 3 j n} R_{i 3 j n}+C_{i 3 j n} \dot{R}_{i 3 j n}, \\
& F_{i 4 j n}=K_{i 4 j n} R_{i 4 j n}+C_{i 4 j n} \dot{R}_{i 4 j n} .
\end{aligned}
$$

\section{Curving track beam model}

\subsection{Track beam roughness}

According to the ISO8608[15], the pavement power spectral density (PSD) can be expressed as follows:

$$
G_{q}(\Omega)=\frac{\alpha}{\Omega^{n}+\beta^{n}}=G_{q}\left(\Omega_{0}\right)\left(\frac{\Omega_{0}}{\Omega}\right)^{-n},
$$

where: $\Omega$ is spatial Frequency; $n$ is frequency index. In this paper, grade A pavement is used for simulation.

\subsection{Track modelling}

Considering the transition curve, longitudinal gradient, curve superelevation, indirect track joints and track turnout structure, a track beam model is established. The width of the track is $690 \mathrm{~mm}$. The curve superelevation rate is calculated by Eq. (17).

$$
\delta=\tan (\gamma)=\frac{V^{2}}{g R},
$$

where: $\delta$ indicates curve superelevation rate; $\gamma$ indicates curve superelevation angle; $V$ is monorail vehicle velocity; $g$ is gravity acceleration; $R$ is rail curve radius.

Fig. 3 shows the change of superelevation angle of track with curve radius of 100 and superelevation rate of $9 \%$.

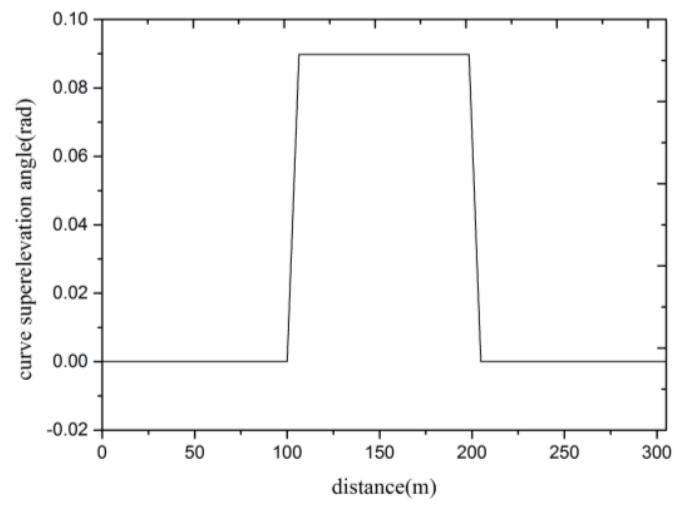

Fig. 3 Change of superelevation angle of track

\section{Comparison between the calculation results and the test results}

In order to verify the accuracy of the method, the test is carried out on a real straddle-type monorail vehicle line, three-direction acceleration sensor is mounted on the vehicle floor and German IMC data acquisition system is adopted, as shown in Fig. 4. 
Figs. 5 and 6 show the comparison between the calculation results and the test results of the spectrum of the vertical acceleration and the lateral acceleration, when monorail vehicle velocity is $15 \mathrm{~km} / \mathrm{h}$. The results show that the main frequency of calculation results and test results is in good agreement, which indicate the accuracy of the calculation method in this paper.

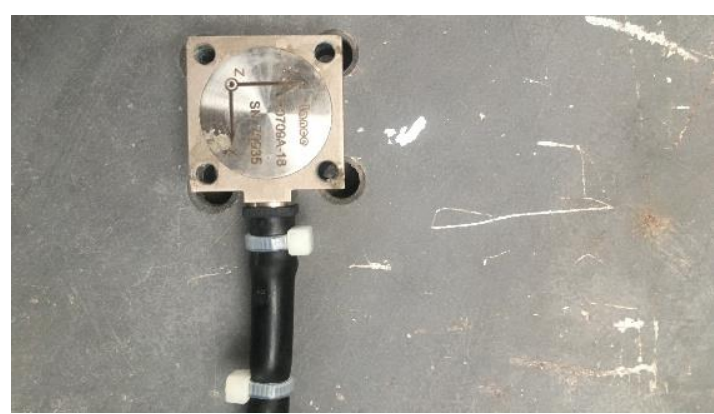

a) Three-direction acceleration sensor

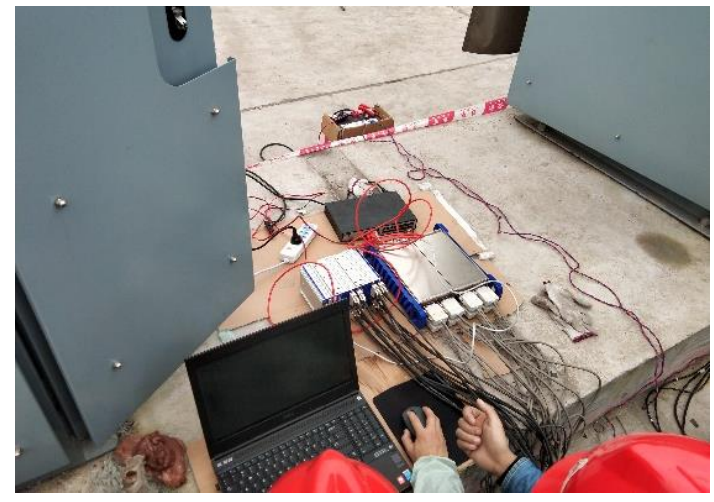

b) German IMC data acquisition system

Fig. 4 Vibration acceleration test system of monorail vehicle

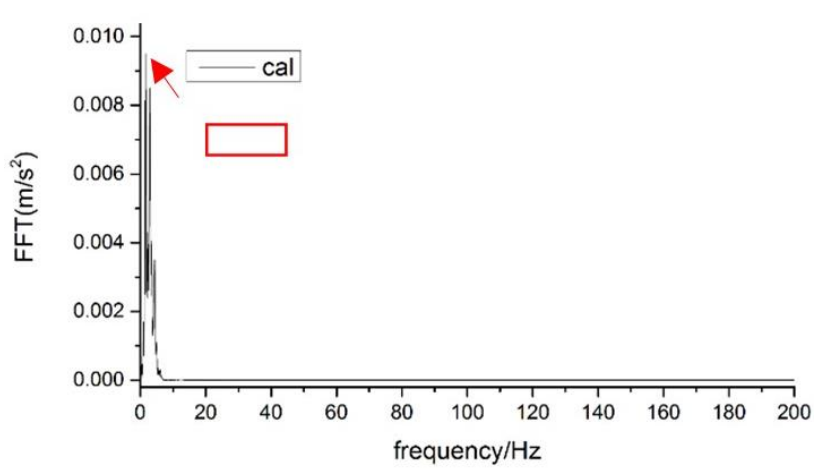

a) Calculation result

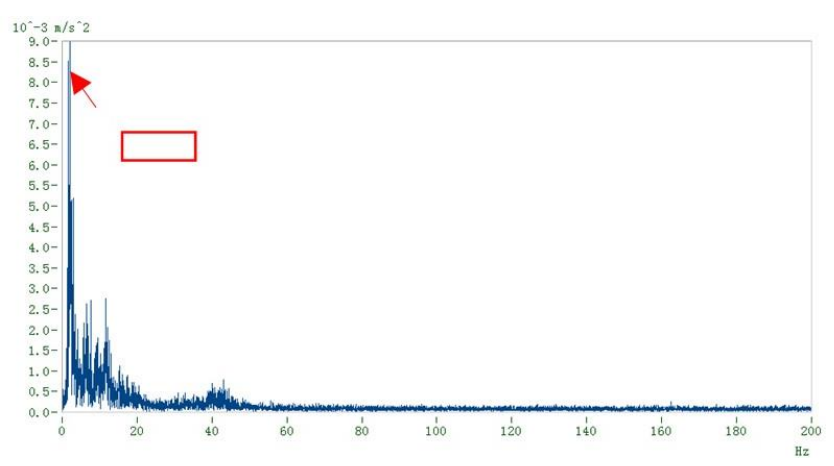

b) Test result

Fig. 5 Spectrum of vertical acceleration $(V=15 \mathrm{~km} / \mathrm{h})$

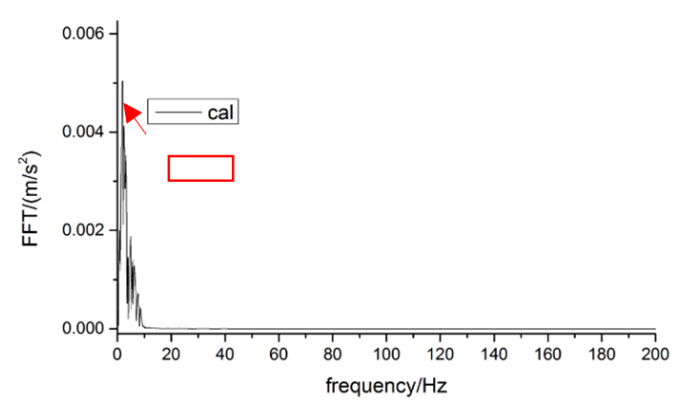

a) Calculation result

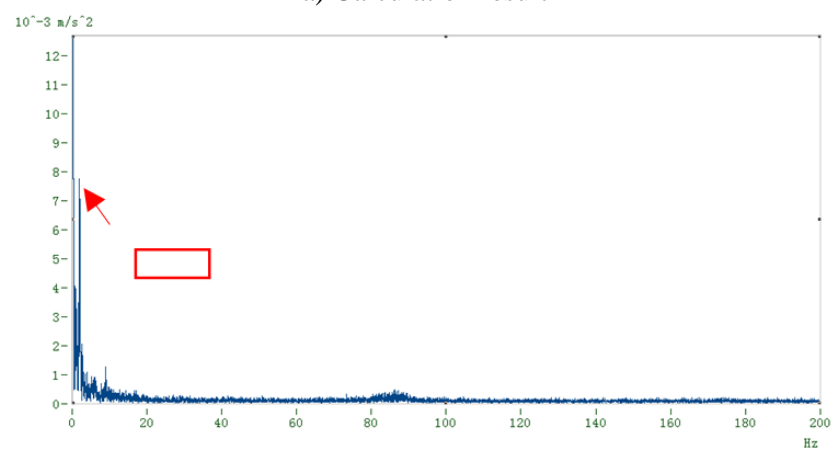

b) Test result

Fig. 6 Spectrum of lateral acceleration $(V=15 \mathrm{~km} / \mathrm{h})$

\section{Results and discussion}

When the monorail vehicle is running, its vibration response characteristics directly affect the running quality. The vibration response of vehicles depends on the track parameters and vehicle parameters. Track parameters mainly include curve radius, curve superelevation rate, vehicle parameters mainly include passenger mass and stiffness of driving wheel.

\subsection{Curve radius}

The calculation conditions of different curve radius are illustrated in Table 3. The acceleration time history curve of different curve radius is shown in Fig. 7 (the left figure is lateral acceleration; the right figure is vertical acceleration). The comparison of the acceleration root mean square (RMS) is shown in Fig. 8. According to Fig. 7 and Fig. 8, the lateral acceleration increases significantly with the decrease of curve radius, while the vertical acceleration does not change significantly.

Table 3

Calculation conditions of different curve radius

\begin{tabular}{|c|c|c|c|c|}
\hline Case & $\begin{array}{c}\text { Curve } \\
\text { radius, } \mathrm{m}\end{array}$ & $\begin{array}{c}\text { Curve superele- } \\
\text { vation rate, } \%\end{array}$ & $\begin{array}{c}\text { Velocity, } \\
\mathrm{km} / \mathrm{h}\end{array}$ & $\begin{array}{c}\text { Curve speed } \\
\text { limit [16] }\end{array}$ \\
\hline A1 & 50 & 9 & 30 & 31.3 \\
\hline A2 & 100 & 9 & 30 & 44.3 \\
\hline A3 & 200 & 9 & 30 & 62.7 \\
\hline
\end{tabular}

\subsection{Curve superelevation rate}

The calculation conditions of different curve superelevation rate are illustrated in Table 4. The comparison of acceleration RMS of different curve superelevation rate is shown in Fig. 9. The lateral and vertical acceleration has little change, and the curve superelevation rate has little effect on the dynamic response of monorail vehicles. 

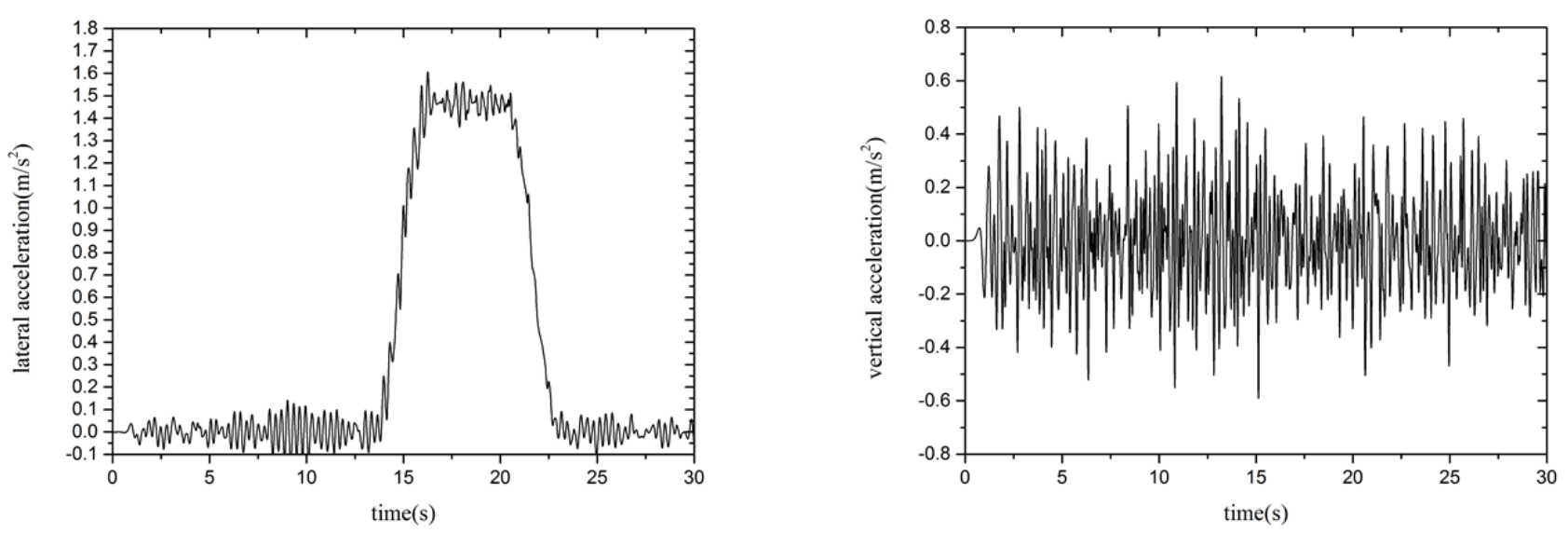

a) $R=50$
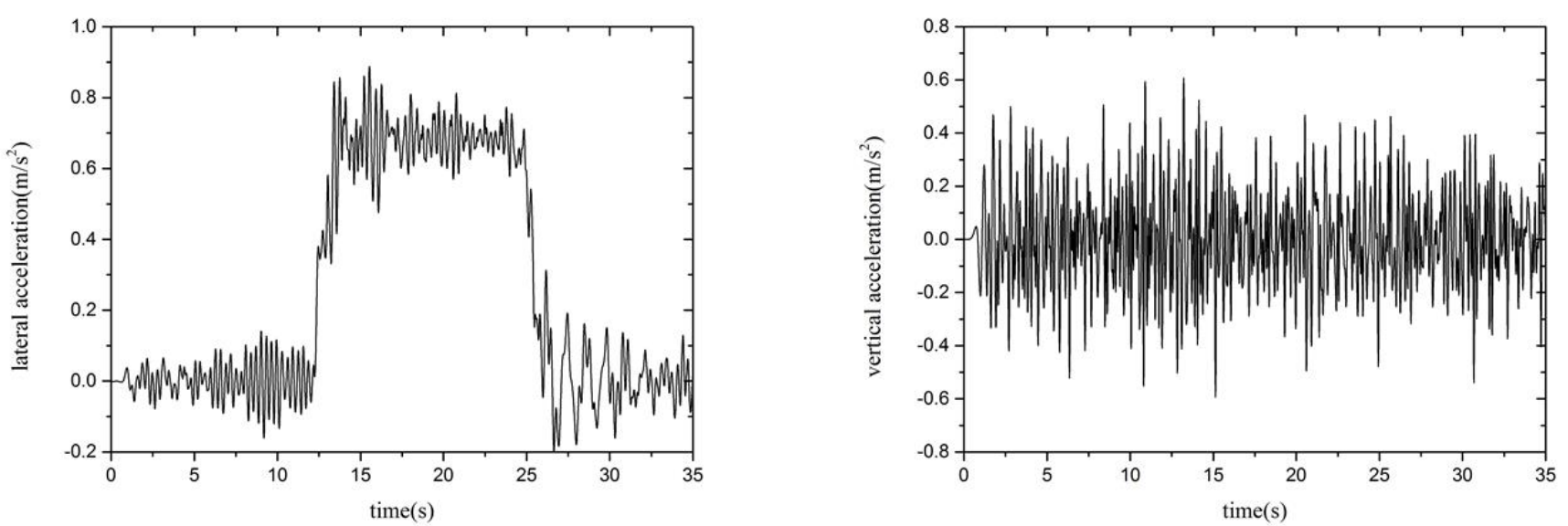

b) $R=100$
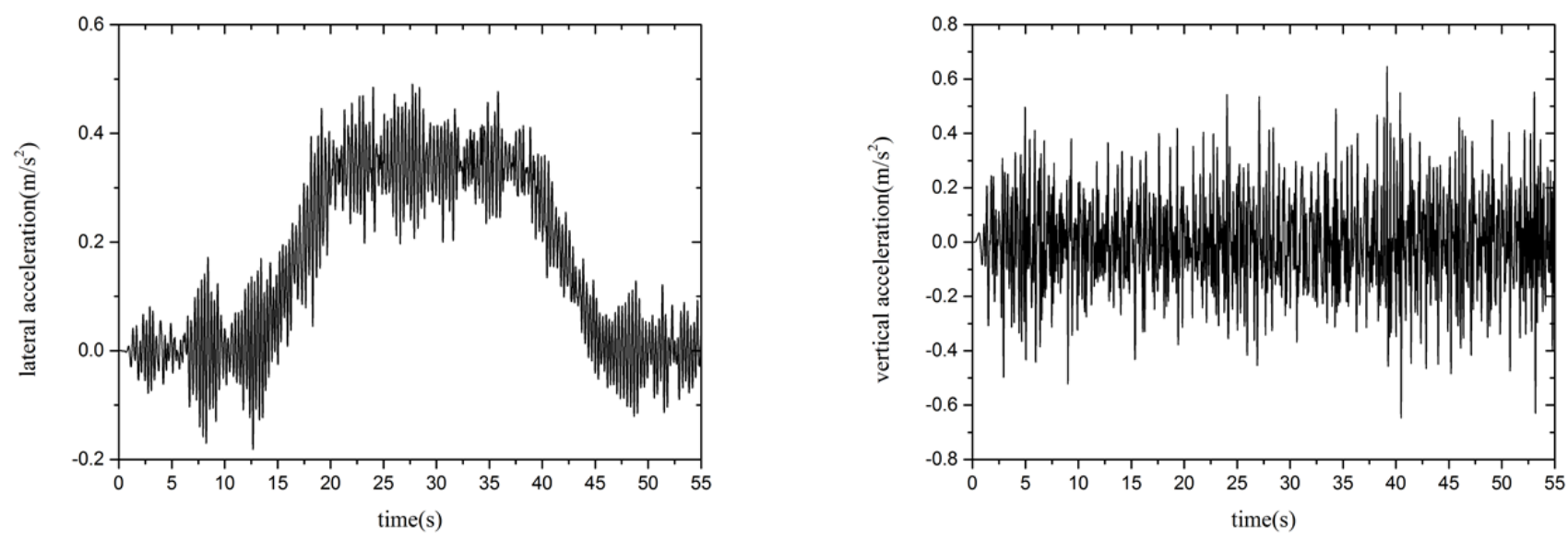

c) $R=200$

Fig. 7 Acceleration time history curve of different curve radius

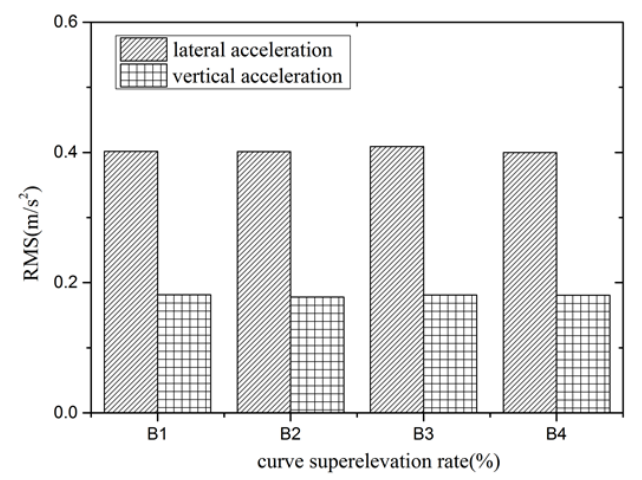

Fig. 8 Influence on different curve radius

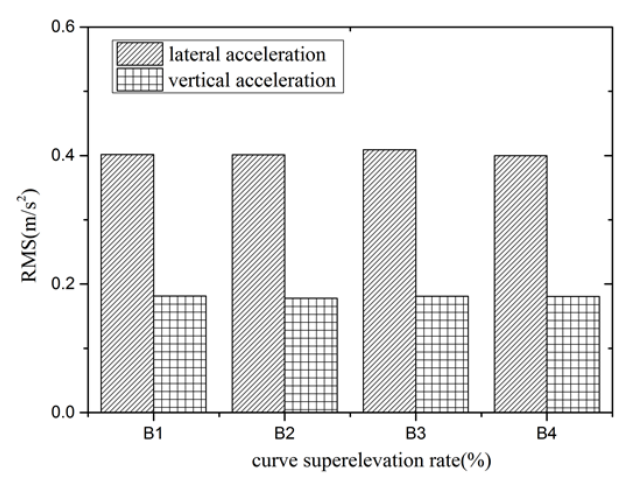

Fig. 9 Influence on different curve superelevation rate 
Table 4 axle bogie is taken as the research object in this paper. A

Calculation conditions of different curve superelevation rate

\begin{tabular}{|c|c|c|c|c|}
\hline Case & $\begin{array}{c}\text { Curve superele- } \\
\text { vation rate, } \%\end{array}$ & $\begin{array}{c}\text { Curve } \\
\text { radius, } \mathrm{m}\end{array}$ & $\begin{array}{l}\text { Velocity, } \\
\mathrm{km} / \mathrm{h}\end{array}$ & $\begin{array}{c}\text { Curve speed } \\
\text { limit [16] }\end{array}$ \\
\hline B1 & 3 & 100 & 30 & 34.7 \\
\hline B2 & 6 & 100 & 30 & 39.8 \\
\hline B3 & 9 & 100 & 30 & 44.3 \\
\hline
\end{tabular}

\subsection{Passenger mass}

The comparison of acceleration RMS of different passenger mass is shown in Fig. 10, the mass for AW0 is $15500 \mathrm{~kg}$, AW2 is $25020 \mathrm{~kg}$, AW3 is $27820 \mathrm{~kg}$ [17]. The lateral and vertical accelerations decrease with the increase of passenger mass, and the vertical acceleration changes more obviously.

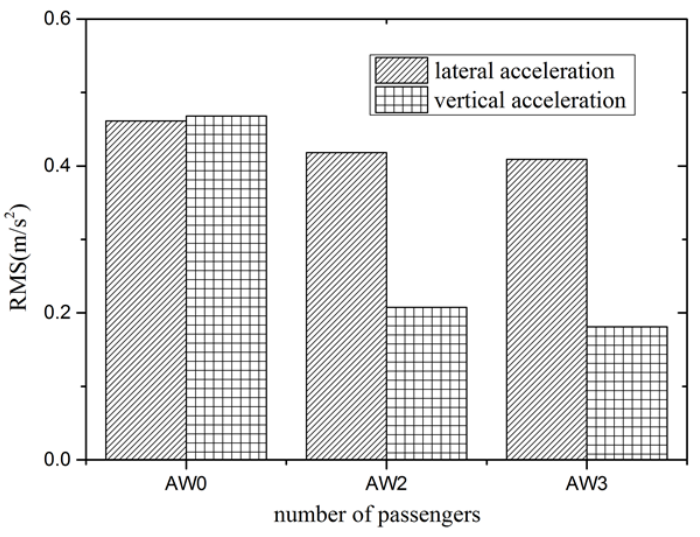

Fig. 10 Influence on different passenger mass

\subsection{Stiffness of driving wheel}

The comparison of acceleration RMS of different stiffness of driving wheel is illustrated in Fig.11, the stiffness for $\mathrm{C} 1$ is $1.2 \times 10^{6} \mathrm{~N} / \mathrm{m}, \mathrm{C} 2$ is $2.4 \times 10^{6} \mathrm{~N} / \mathrm{m}, \mathrm{C} 3$ is $3.6 \times 10^{6} \mathrm{~N} / \mathrm{m}$. The curve radius is $100 \mathrm{~m}$, the curve superelevation rate is $9 \%$, and the vehicle velocity is 30 $\mathrm{km} / \mathrm{h}$. The lateral acceleration and vertical acceleration increase with the increase of the stiffness of driving wheel, so it is necessary to consider the reasonable stiffness of driving wheel in vehicle design.

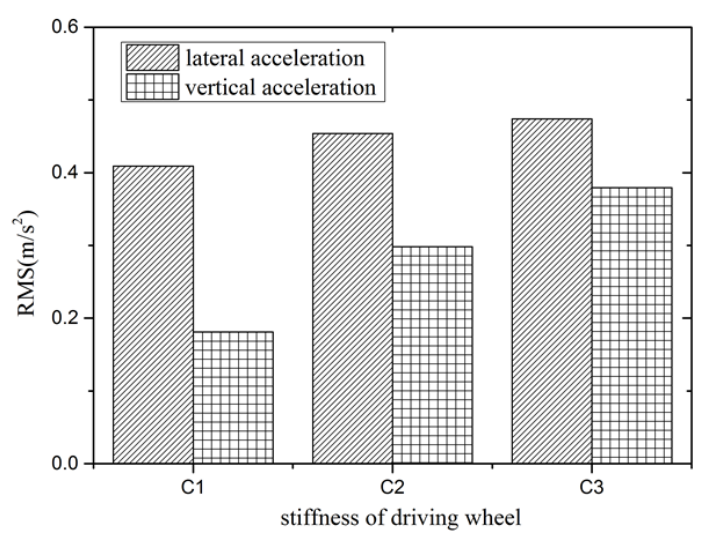

Fig. 11 Influence on stiffness of driving wheel

\section{Conclusions}

The straddle-type monorail vehicle with single-
15 degrees-of-freedom (DOF) dynamic model is established, and the wheel-rail contact model and the curving track beam model are created. Compared with the test results, the accuracy of the method is verified. According to research results:

1) The lateral acceleration increases with the decrease of curve radius, but the vertical vibration acceleration does not.

2) The curve superelevation rate has little effect on the lateral and vertical vibration of monorail vehicles.

3) The lateral and vertical accelerations decrease with the increase of passenger mass, and the vertical acceleration changes more obviously.

4) The lateral and vertical accelerations increase with the increase of the stiffness of driving wheel.

The research in this paper can provide theoretical reference for the subsequent design and development of straddle-type monorail vehicle with single-axle bogie.

\section{Acknowledgments}

This work was supported by the Chongqing Key Laboratory of Urban Rail Transit System Integration and Control Open Fund (Grant No. CKLURTSIC-KFKT202003 and CKLURTSIC-KFKT-202009).

\section{References}

1. Peter, P. E. 2015. Why monorail systems provide a great solution for metropolitan areas, Urban Rail Transit $1(1): 13-25$.

http://dx.doi.org/10.1007/s40864-015-0001-1.

2. Kuwabara, T.; Hiraishi, M.; Goda, K.; et al. 2005. New solution for urban traffic: small-type monorail system, 10th International Conference on Automated People 2005: 1-7. http://dx.doi.org/10.1061/40766(174)65.

3. Sekitani, T.; Hiraishi, M.; Yamasaki, S.; et al. 2005. China's first urban monorail system in Chongqing, Hitachi Review 54(4):193-197.

4. Xia, Z. 2016. Improvement and innovation of bombardier monorail technology, Modern Urban Transit 29(2): 96-103.

5. Goda, K.; Nishigaito, T.; Hiraishi, M.; et al. 2002. Improving curving performance for articulated-type small monorail car, Transactions of the Japan Society of Mechanical Engineers C 68(627): 2410-2417. http://dx.doi.org/10.1299/kikaic.68.2410.

6. Goda, K.; Hiraishi, M.; Iwasaki, K. 1999. Response analysis caused by track irregularity for a monorail, Transactions of the Japan Society of Mechanical Engineers C 65 (637):3546-3552.

7. Lee, C.H.; Kim, C.W.; Kawatani, M.; et al. 2005. Dynamic response analysis of monorail bridges under moving trains and riding comfort of trains, Engineering Structures 27 (14):1999-2013. http://dx.doi.org/10.1016/j.engstruct.2005.06.014.

8. Lee, C.H.; Kawatani, M.; Kim, C.W.; et al. 2006. Dynamic response of a monorail steel bridge under a moving train, Journal of Sound and Vibration 294 (3): 562-579. http://dx.doi.org/10.1016/j.jsv.2005.12.028. 
9. Naeimi, M.; Tatari, M.; Esmaeilzadeh, A.; et al. 2015. Dynamic interaction of the monorail-bridge system using a combined finite element multibody-based model, Proceedings of the Institution of Mechanical Engineers, Part K: Journal of Multi-body Dynamics 229 (2): 132-151.

10. Goda, K.; Nishigaito, T.; Hiraishi, M.; et al. 2000. A curving simulation for a monorail car, Proceedings of the 2000 ASME/IEEE Joint Railroad Conference, Newark, NJ, USA: 171-177. http://dx.doi.org/10.1109/RRCON.2000.869998.

11. Wang, H.; Zhu, E.; Chen, Z. 2017. Dynamic response analysis of the straddle-type monorail bridge - vehicle coupling system, Urban Rail Transit 3: 172-181. http://dx.doi.org/10.1007/s40864-017-0069-x.

12. Maciel, G. P. R.; Barbosa, R. S. 2016. Monorail vehicle model to study influence of tyre modelling on overall dynamics, International Journal of Heavy Vehicle Systems 23 (4):317-322.

13. Jiang, Y.; Wu, P.; Zeng, J.; et al. 2019. Detection and alleviation of the abnormal vibration of the monorail based on experiment and simulation, Journal of Low Frequency Noise Vibration and Active Control 38 (3):282-295. http://dx.doi.org/10.1177/1461348419825605.

14. Thomson, W.T. 1988. Theory of Vibration with Applications, Prentice Hall, $196-198$ p.

15. Bao, Y.; Li, Y.; Ding, J. 2016. A case study of dynamic response analysis and safety assessment for a suspended monorail system, International Journal of Environmental Research and Public Health 13(11): 11211137. http://dx.doi.org/10.3390/ijerph13111121.

16. Ji, Y.; Ren, L. 2018. Anti-overturning capacity and critical roll angle of straddling monorail vehicle, Proceedings of the Institution of Mechanical Engineers,
Part C: Journal of Mechanical Engineering Science 232 (23):4420-4429. http://dx.doi.org/10.1177/0954406217753234.

17. Janjic, D. 2013. Dynamic train-bridge interaction in monorail Sao Paulo metro line 2, International Association for Bridge and Structural Engineering 101 (20):18. http://dx.doi.org/XX.XXX/(XXX)XX-XX(XXX)X:X.

Liang XIN, Zixue DU, Junchao ZHOU, Zhen YANG, Zhouzhou XU

\section{STUDY ON DYNAMIC RESPONSE OF STRADDLE- TYPE MONORAIL VEHICLE WITH SINGLE-AXLE BOGIE UNDER CURVE CONDITION}

$\mathrm{S} \mathrm{u} \mathrm{m} \mathrm{m} \mathrm{a} \mathrm{r} \mathrm{y}$

This paper is concerned with the dynamic response of straddle-monorail with single-axle bogie under curve condition. A 15 degrees-of-freedom(DOF) dynamic model is established for straddle-type monorail vehicle with single-axle bogie, which consists driving wheels, steering wheels and stabilizing wheels. The motion equations of the straddle-type monorail vehicle are derived using the Lagrange's equation, and the wheel-rail contact model and the curving track beam model are created. Compared with the test results, the accuracy of the method is verified. Finally, the influence of curve radius, curve superelevation rate, number of passengers and stiffness of driving wheels on dynamic response is discussed.

Keywords: straddle-type monorail vehicles, single-axle bogie, curve condition, dynamic response.

Received February 17, 2020 Accepted April 07, 2021 